\title{
NOGUERA FERNÁNDEZ, Albert La ideología de la soberanía. Hacia una reconstrucción emancipadora del constitucionalismo
}

Madrid: Taurus, 2019, 162 pàg.

\author{
Aarón Hocasar de Blas \\ UNIVERSITAT DE VALÈNCIA \\ ahodedalumni.uv.es
}

Clara Cortés Tasa

UNIVERSITAT DE VALÈNCIA

clacortađalumni.uv.es

La ideología de la soberanía és la publicació més recent d'Albert Noguera, politòleg, jurista i professor de Dret Constitucional a la Universitat de València. En aquesta obra podem diferenciar clarament tres parts. En primer lloc, els dos primers capítols tracten d'analitzar, a través d'un cert treball historiogràfic, l'estat actual de la sobirania i la distribució de poders. En segon lloc, en els capítols tercer i quart s'argumenta la impossibilitat o animadversió de certs projectes constitucionals. Finalment, en el capítol final, Noguera ens ofereix una guia orientativa, un full de ruta constitucional alternatiu, i explica el seu potencial emancipador, així com el seu sentit i la seua aplicació en l'actualitat.

Si entrem directament en l'obra, la tesi principal és que vivim una contradicció de la sobirania que dificulta la construcció d'un projecte politicoconstitucional emancipador i garantista per part de l'esquerra. Aquesta tesi naix de la paradoxa generada per l'acceptació generalitzada que la noció moderna de so- birania com a forma d'organització del poder i de la societat està en crisi, i en la simultània formulació de propostes per a superar-la basades en la ideologia de la sobirania.

Inicialment, a partir d'un cert recorregut històric, l'autor il-lustra el procés de gènesi de la sobirania com a forma de producció social pròpia de la Modernitat, és a dir, com s'ha constituït com una unitat orgànica historicoconcreta entre una forma d'organització de les relacions socioeconòmiques i una ideologia que la legitima. Així, la ideologia de la sobirania es defineix pels seus dos supòsits essencials: l'existència d'un únic nucli organitzador de la societat des del qual emana el poder i l'existència d'una connexió exclusiva entre aquest nucli i un únic dret vàlid i legítim. Noguera hi assenyala que actualment l'estat experimenta una doble tendència: d'una banda, cap a la integració o l'homogeneïtzació global, amb la corresponent erosió de la seua autonomia en benefici de poders supranacionals, $\mathrm{i}$ 
de l'altra, cap a la fragmentació o la diferenciació de les formes d'exercici de la ciutadania, fet que dona lloc a nous grups vulnerables en condicions de no-drets o drets més limitats, per als quals la via alternativa d'accés a la ciutadania i a la inclusió en la societat es dona per mitjà de canals no estatals. Com a resultat d'aquest procés, vivim una superposició d'espais-temps històrics, cadascun amb el seu propi centre de poder - el preliberal de la comunalització, el liberal de l'estat i el postliberal de la globalització-, és a dir, el camp dels drets hauria esdevingut més complex a causa de la substitució de la forma d'organització política i social pròpia de la noció moderna de sobirania per formes policèntriques, cadascuna amb els seus propis subjectes $\mathrm{i}$ mitjans de garantia i vulneració de drets. En aquest punt cal destacar la reformulació que fa l'autor de la tradicional dicotomia estat-societat: identifica l'estat amb l'espai d'allò que és públic i la societat amb l'espai d'allò que és privat i té utilitat pública; així, fa més complex el camp de la lluita dels drets, constituït per tres eixos: el clàssic eix publicoprivat, la utilitat pública —amb la seua potencialitat cooperativa o extractiva- i l'entorn de relacions interestatals, que pot ser igualitari o desigualitari. D'aquesta manera naix la contradicció de la sobirania: l'estat ha quedat reduït a la funció directiva per mitjà de la desagregació de funcions cap a la societat, mentre que l'esquerra política resulta incapaç de reconciliar els tres centres de poder i continua construint alternatives des de l'estatcentrisme. En contraposició, Noguera postula que un projecte polític garantista ha d'operar en la realitat policèntrica, i això requereix una reconstrucció del constitucionalisme que permeta la superació de la ideologia de la sobirania mitjançant una redefinició.

En aquesta obra s'estudien tres projectes polítics amb una posició que varia significativament respecte de la ideologia de la sobirania. En primer lloc, l'autor repassa l'hiperconstitucionalisme, que pretén un enfortiment de la ideologia de la sobirania, a partir de la proposta de Luigi Ferrajoli, el qual en constitueix el màxim exponent. La tesi principal de Ferrajoli és que, per tal de fer front als poders salvatges propis de la globalització i generar justícia social, cal recuperar un estat constitucional enfortit $i$ ampliat.

Aquest projecte, segons Noguera, presenta dos problemes essencials. En primer lloc, un enfortiment de l'Estat i un debilitament de la societat en un moment en què la tendència real és la contrària; a més, la seua implantació requereix determinades condicions objectives - com a mecanismes de garantia dels drets- i subjectives - pròpies d'una cultura basada en el patriotisme constitucional que tampoc s'hi donen, fet que planteja dificultats reals, estructurals i culturals per a una implantació efectiva.

En segon lloc, analitza el model del postconstitucionalisme, que es fonamentaria en l'abolició de la ideologia de la sobirania, ja que apunta a noves realitats sense Constitució, i afirma al respecte que «sin constitucionalismo no hay posibilidad de construir una sociedad con dignidad, seguridad ni garantía de los derechos». Segons Noguera, els elements constitutius del constitucionalisme, immanents a qualsevol constitució, són la sistematicitat i l'establiment de límits al poder, que estan sent erosionats a causa de la superposició de diferents espais-temps històrics amb les seues pròpies formes de juridicitat, de vegades contradictòries. Així, amb la supressió del constitucionalisme com a forma d'ordenació sistematitzada i limitada de la relació entre dominadors i dominats, es preveu la tendència cap a formes de pluralisme distòpiques en què no operaria cap element d'unitat, de manera que resultaria impossible la construcció de projectes de dignitat humana. En suma, la desintegració sistèmica de la societat pròpia de societats sense constitucionalisme ni unitat en un context de capitalisme degeneratiu i d'hiperexplotació conduiria a una societat de naturalesa hobbesiana.

Finalment, davant la conjunció de diversos factors que exigeixen nous paradigmes juridicoconstitucionals - l'esgotament de l'estratègia tant reformista com revolucionària, la deriva degenerativa d'un capitalisme terminal i la incapacitat de les propostes anteriors per a constituir-se com a projectes polítics 
garantistes-, Noguera planteja una redefinició de la teoria de la sobirania. L'alterconstitucionalisme supera l'antítesi reforma-revolució i la reconcilia amb una estratègia de reformisme revolucionari orientada a un nou sistema de relacions socials, polítiques, econòmiques i culturals anticapitalista i construït des del constitucionalisme.

En l'actualitat, la vella antítesi entre revolució i reforma es reformula en una nova confrontació entre dos tipus de reformisme: un de subjecte, objecte i pràctica singular, que ha passat a ser inoperant, enfront d'un altre, un nou reformisme de subjecte, objecte i pràctiques plurals amb potencial transformador, és a dir, un reformisme revolucionari. La complicació del camp dels drets i la fragmentació i superposició de distintes lògiques d'explotació que l'acompanyen han provocat que les pràctiques de conflicte que operen dins del marc capitalista per a disminuir les quotes d'explotació i millorar les condicions de vida de les classes treballadores ja no puguen adoptar fórmules de reformisme de subjecte, objecte i pràctiques singulars capaces d'actuar únicament en l'eix publicoprivat, sinó que exigeixen una diversificació de les formes d'organització del col-lectiu i les pràctiques de conflicte que operen simultàniament en els tres eixos de disputa de drets. A més, les diferents formes d'organització del col-lectiu en cada eix no constitueixen únicament estructures de lluita, sinó que també prefiguren un nou orde social, polític i econòmic.

Noguera preveu que la transició cap a noves formes d'alterconstitucionalisme pot durar tot el segle xxI, ja que no pot tancar-se un full de ruta, sinó que s'ha d'anar avançant empíricament a partir d'encerts i errors. En aquest marc, les experiències d'autoorganització popular constitueixen l'avantguarda, mentre que la teoria és la rereguarda. Així, per activar un reformisme plural es requereix una dialèctica entre un dret constitucional menor d'anticipació i de consumació, és a dir, la utilització del dret per a facilitar la creació d'espais d'utilitat pública cooperativa que desenvolupen una funció promotora i educativa al voltant d'aquest tipus d'institucions d'autoorganització social. Aquest procés implica una desestatització parcial de la regulació social i una pèrdua de centralitat del poder de l'estat, la qual cosa produiria una desorganització del dret oficial, que coexistiria amb un dret no oficial emanat de legisladors fàctics que compliquen i diversifiquen les formes de juridicitat i vida social. No obstant això, aquestes formes de pluralisme haurien d'estar cohesionades per formes d'universalisme, i el principal instrument democràtic d'universalisme amb capacitat de sistematitzar l'espai social al voltant de valors d'unitat és la Constitució, que constitueix un instrument juridicopolític a través del qual s'articula una ideologia. Noguera conclou que la Constitució de l'alterconstitucionalisme ha de ser producte d'un procés constituent ampliat que adopte la fórmula diversitat-sobiranies-Konstitution, fet que implicaria la institucionalització de formes d'organització i sistematització social pluralistes que superen l'estat liberal modern: una institucionalitat política d'horitzontalitat asimètrica i desordenada que no només supose el reconeixement de les múltiples formes de pluralisme econòmic i associativitat social sinó que també opere en sintonia amb una nova racionalitat descentralitzadora-comunal basada en la necessitat de coordinar i facilitar recursivament formes d'organització estatal amb altres d'autoorganització i cooperació social.

Pel que fa al comentari crític de l'obra, podem ressaltar diferents aspectes. En primer lloc, i fent al-lusió directament a les primeres impressions que ens va provocar la lectura del llibre, trobem a faltar dades empíriques que reforcen la postura de l'autor. En aquest sentit, els postulats de l'obra es fonamenten en una infinitat de citacions bibliogràfiques, motiu pel qual es tracta de manera quasi integral d'una dissertació teòrica en què l'únic contacte directe $\mathrm{amb}$ la realitat social de l'autor són les dades que aporten les seues fonts de manera secundària. Aquesta crítica es fa evident sobretot en els apartats dedicats a l'eix de la utilitat pública col-laborativa, en què les afirmacions sobre la proliferació de xarxes ciutadanes 
de suport mutu per a suplir els espais que l'estat ha anat abandonant després del seu replegament neoliberal podrien haver apel-lat a estadístiques de capital social -en el sentit més politològic de Robert Putnam i no en el sociològic de Pierre Bourdieu- o a experiències concretes que hagen tingut lloc en la societat civil per a combatre les grans plataformes de la utilitat pública extractiva. En aquesta línia, s’hi podrien haver comentat iniciatives com la de Libelista, una xarxa de llibreries que es va associar per a competir contra Amazon (Agències, 2017) o s'hi podria haver parlat d'accions ciutadanes concretes en diferents municipis, i no simplement versar, en abstracte, sobre grups de comaternitat o bancs de llibres sense cap suport empíric sobre la seua constatació material en la realitat. Així mateix, ens pareix més sorprenent que en l'apartat dedicat a l'economia de l'alterconstitucionalisme Noguera sí que hi indique exemples concrets de cooperatives afectades per la crisi econòmica de l'any 2008, quan aquest aspecte podria haver estat sigut més intuïtiu i versemblant $i$ se'n podria haver prescindit del reforç empíric.

D'altra banda, el fet que d'aquest tipus d'associacions, se n'espere un paper de primer ordre en la construcció del model constitucional emancipador que ens proposa no proporciona gaire seguretat. En aquest punt, considerem que l'autor pot estar intentant exportar esquemes de praxi pertanyents a altres tradicions polítiques la implantació dels quals en els països de l'òrbita europea pot ser qüestionable i generar una certa incertesa pel que fa a la viabilitat del model. És sabut que Noguera ha treballat i estudiat sobre la situació política i social a Amèrica Llatina, on aquest tipus de projectes sí que hi han tingut una presència significativa. No obstant això, si posem com a exemple Espanya, el nivell de capital social —amb l'excepció dels territoris de Catalunya, el País Basc i Navarraés relativament baix (Subirats, 2008: 653-656), per la qual cosa, malgrat que la proposta es planteja a llarg termini, a priori no pareix un plantejament significativament sòlid pel que fa a l'espai preliberal.

Finalment, si fem especulacions en un to més pervers, ens pareix quasi inevitable qüestionar l'apli- cabilitat del model alterconstitucional després de la conjuntura crítica generada per la COVID-19, perquè no seria la primera vegada en la història que un fenomen d'aquest tipus fa virar el rumb que els esdeveniments socials pareixien prendre amb relativa autonomia. Per exemple, els canvis en l'estructura de la propietat de la terra provocats per la pesta negra van ser determinants en les diferències posteriors entre l'est i l'oest d'Europa (Acemoglu i Robinson, 2018: 125). És per això que dedicarem la resta del comentari a la vigència del llibre després que, en paraules de David Harvey, el virus punxara la història (Harvey, 2020: 85). I és que, tot i tractar-se d'una obra recent, la seua vigència podria quedar sepultada per un escenari en què s'ha produït una radicalització d'allò que Michel Foucault denominava la biopolítica, és a dir, «la forma en què, a partir del segle XVIII, s'han intentat racionalitzar els problemes que plantejaven per a la pràctica governamental fenòmens propis d'un conjunt d'éssers vius constituïts com a població» (Foucault, 2016: 206).

En primer lloc, en una de les seues habituals columnes d'opinió publicada pocs dies abans de l'inici del confinament a Espanya, Noguera argumentava que aquesta crisi suposaria l'avantsala de grans mesures de reajustament estructural en un escenari en què l'opció d'esquerra no és prou forta per a construir una hegemonia (Noguera, 2020), perquè les úniques opcions que hi podrien aspirar estarien formant part de l'executiu, de manera que les opcions de dreta serien les que canalitzarien el descontentament. Així doncs, estava platejant un escenari semblant al de l'any 2008, en què les mesures de reajustament van ser la reforma del 135 de la Constitució i la política econòmica de la troica, i el descontentament es va canalitzar per part de la dreta en la victòria del PP el 2011, després de la massiva abstenció d'habituals votants socialistes. Aquest mateix esquema ja havia sigut plantejat per Noguera pocs mesos abans en relació amb la llavors vaticinada recessió econòmica, article en què recomanava a Unides Podem no entrar en l'executiu per a poder constituir-se com a alternativa de govern després de la conjuntura (Noguera, 2019b). 
Aquest pessimisme no ha sigut compartit per algunes figures rellevants de l'esquerra. Per exemple, David Harvey considera que aquesta «venganza de la naturaleza por más de cuarenta años de grosero y abusivo maltrato a manos de un violento y desregulado extractivismo neoliberal» farà que, probablement, els Estats Units es vegen obligats a prendre mesures molt més intervencionistes que qualsevol proposta formulada per Sanders, i això, sota l'administració Trump (Harvey, 2020: 88-96).

Així mateix, pel que fa a Ferrajoli, malgrat que la seua proposta hiperconstitucionalista puga percebre's com a anacrònica en l'escenari de la globalització a causa de la pèrdua de poder dels leviatans estatals, aquesta conjuntura ha fet que alguns dels seus postulats recuperen força. Durant la pandèmia hem contemplat com els estats recuperaven antics espais d'acció amb l'objectiu de garantir determinats serveis bàsics. Així, aquests fets estan projectant de cara al futur un escenari discursiu, diferent del 2008, en què la necessitat d'un sector públic fort estiga representada en el joc simbòlic de l'arena política amb la finalitat de fer possible l'adopció de mesures corresponents a aquestes posicions discursives semblants a les propostes de Ferrajoli. A més, a causa del fet que l'impacte del virus no entenga de fronteres entre estats, una altra de les seues idees en auge és la de la «constitució planetària» com a fórmula de garantia de drets global (Dezordi Wermuth i Bolzan de Morais, 2020: 13-18) per tal de lligar l'espai-temps liberal amb el postliberal.

Des de la nostra perspectiva, no afirmem que inevitablement estem davant del gran moment de la transformació radical, però sí que en el moment actual s'eixamplen els marges d'allò contingent. Així doncs, de la mateixa manera que la marginal escola econòmica neoliberal va poder aprofitar la crisi del petroli del 1973 per posar-se en la primera línia d'allò ideològic, és possible que el descontentament es canalitze des de sectors de l'esquerra amb vista a algun tipus de canvi. En contraposició al pessimisme de Hayek, Milton Friedman deia: «Solamente una crisis, ya sea real o percibida, pro- duce un cambio real. Cuando llega la crisis, las acciones que se emprenden dependen de las ideas que haya disponibles, [...] lo políticamente imposible se vuelve políticamente inevitable» (Jones, 2014: 45). Des d'aquesta perspectiva, s'obrin les possibilitats de transformació i és possible - tot i que no inevitable- que d'aquesta situació sorgisca un escenari d'emancipació col-lectiva. D'aquesta manera, el 2020 ja no seria la repetició del triomf de la dreta del 2008, com afirma Noguera, sinó que, en tot cas, correspondria amb el que l'any 1973 va ser la victòria de Thatcher i Reagan, però aquesta vegada protagonitzada pels seus antagonistes ideològics. L'any 2008 ja no es veuria com un punt de retorn, sinó com un precedent, de la mateixa manera que, per exemple, el 1905 ho és per al 1917. Dit això, no pretenem afirmar deterministament el rumb que prendran els esdeveniments després de la conjuntura, sinó que, davant d'aquesta conjuntura, més projectes poden ser possibles enfront de la inestabilitat d'allò extraordinari, fins i tot l'agrupació de determinats elements que acaben desembocant en alguna fórmula semblant a l'alterconstitucionalisme de Noguera.

A manera de conclusió i tornant al contingut del llibre, considerem que, a pesar de les apreciacions comentades, Noguera du a terme un treball d'anàlisi i síntesi impecable, en el qual condensa una immensa bibliografia de diferents disciplines en una obra breu sense perdre gens de rigor i en un to d'allò més divulgatiu. Així mateix, destaquem positivament el fet que no caiga en una visió unilineal i determinista, típica en alguns marxistes. Contràriament, contempla diferents dimensions i variables que han de ser considerades i harmonitzades per a construir una praxi integral en què el full de ruta no és una recepta tancada, sinó que es va construint i perfeccionant al mateix temps que es fa, avançant empíricament a partir de dinàmiques d'assaig i error. Finalment, creiem que la major aportació de l'obra és el fet que se sintetitzen diversos postulats de les ciències socials i es traslladen a l'àmbit del dret, de manera que es tendeixen ponts entre ambdues disciplines per a la construcció d'una praxi de visió més holística. 


\section{REFERÈNCIES BIBLIOGRÀFIQUES}

Acemoglu, D. i Robinson, J. A. (2018). Pequeñas diferencias y coyunturas críticas: El peso de la historia. En D. Acemoglu i J. A. Robinson, Por qué fracasan los paises (p. 198-199). Barcelona: Ediciones Deusto.

Agències (2017). Nace el Amazon de las librerías independientes. El Español. 25 de juliol de 2017. https://www.elespanol.com/cultura/libros/20170725/233977137_0.html

Dezordi Wermuth, M. Â. i Bolzan de Morais, J. L. (2020). Da exceção agambeniana à Constituição Planetária de Ferrajoli: desafios impostos pela pandemia do novo coronavírus às categorias jurídico-políticas tradicionais. Revista Electrônica do Curso de Direito da UFSM, 15(1): 1-29. DOI: 10.5902/1981369443057

Foucault, M. (2016). Nacimiento de la biopolítica: Curso 1978-1979. En M. Foucalt, Historia política de la verdad. Una genealogía de la moral. Breviarios de los Cursos del Collège de France (p. 198-199). Madrid: Biblioteca Nueva.

Harvey, D. (2020). Política anticapitalista en tiempos de coronavirus. En P. Amadeo, Sopa de Wuhan. ASPO. Recuperat de http://iips.usac.edu.gt/wp-content/uploads/2020/03/Sopa-de-Wuhan-ASPO.pdf

Jones, O. (2014): El establishment. Barcelona: Editorial Planeta.

Noguera Fernández, A. (2019a). La ideología de la soberanía. Madrid: Taurus.

Noguera Fernández, A. (2019b). El gobierno de coalición como antesala del desastre. eldiario.es. 18 de novembre de 2020. https://www.eldiario.es/contrapoder/Gobierno-coalicion-antesala-desastre_6_964913518.html

Noguera Fernández, A. (2020). La izquierda ante el escenario post-coronavirus. eldiario.es. 16 de març de 2020. https://www.eldiario.es/contrapoder/izquierda-escenario-postcoronavirus_6_1006559348.html

Subirats, J. (2008). ¿Ha servido de algo? Más de veinticinco años de comunidades autónomas en España. Notas para un balance. En M. Jiménez de Parga y Cabrera i F. Vallespín Oña (coord.), La política (p. 198-199). Madrid: Biblioteca Nueva. 